Open Access

\title{
Severe but not mild hypercapnia affects the outcome in patients with severe cardiogenic pulmonary edema treated by non-invasive ventilation
}

Damien Contou ${ }^{1}$, Chiara Fragnoli ${ }^{1}$, Ana Córdoba-Izquierdo ${ }^{1}$, Florence Boissier ${ }^{1}$, Christian Brun-Buisson ${ }^{1}$ and Arnaud W Thille $1,2,3^{*}$

\begin{abstract}
Background: Patients with severe cardiogenic pulmonary edema (CPE) are frequently hypercapnic, possibly because of associated underlying chronic lung disease (CLD). Since hypercapnia has been associated with outcome, we aimed to identify factors associated to hypercapnia and its role on outcome of patients with CPE and no underlying CLD.

Methods: Observational cohort study using data prospectively collected over a 3-year period. After excluding patients with any CLD or obstructive sleep apneas, all patients treated by non-invasive ventilation (NIV) for severe CPE were included. Hypercapnia was defined as $\mathrm{PaCO}_{2}>45 \mathrm{mmHg}$ and non-rapid favorable outcome was defined as the need for intubation or continuation of NIV for more than $48 \mathrm{~h}$.

Results: After excluding 60 patients with underlying CLD or sleep apneas, 112 patients were studied. The rates of intubation and of prolonged NIV were $6.3 \%(n=7)$ and $21.4 \%(n=24)$, respectively. Half of the patients $(n=56)$ had hypercapnia upon admission. Hypercapnic patients were older, more frequently obese, and were more likely to have a respiratory tract infection than non-hypercapnic patients. Hypercapnia had no influence on intubation rate or the need for prolonged NIV. However, patients with severe hypercapnia $\left(\mathrm{PaCO}_{2}>60 \mathrm{mmHg}\right)$ needed longer durations of NIV and intensive care unit (ICU) stay than the others.

Conclusions: Among the patients admitted for severe CPE without CLD, half of them had hypercapnia at admission. Hypercapnic patients were older and more frequently obese but their outcome was similar compared to non-hypercapnic patients. Patients with severe hypercapnia needed longer durations of NIV than the others without increase in intubation rate.
\end{abstract}

Keywords: Intensive care unit; Acute respiratory failure; Cardiogenic pulmonary edema; Non-invasive ventilation; Hypercapnia; Respiratory acidosis

\footnotetext{
* Correspondence: aw.thille@gmail.com

${ }^{1}$ AP-HP, Réanimation Médicale, Groupe Hospitalier Henri Mondor - Albert

Chenevier, Créteil, France

${ }^{2}$ Réanimation Médicale, CHU de Poitiers, 2 rue de la Milétrie, 86021 Poitiers,

France

Full list of author information is available at the end of the article
} 


\section{Background}

Cardiogenic pulmonary edema (CPE) is usually rapidly reversible using appropriate medical therapy including high dose of vasodilators and diuretics [1]. The use of non-invasive ventilation (NIV) induces a more rapid improvement in respiratory distress than does standard oxygen therapy [2] and reduces the need for intubation and mortality of the most severe patients [3-5], with less than $10 \%$ of patients with severe CPE treated with NIV needing intubation $[2,6-12]$.

Hypercapnia is common in patients with severe CPE [13]. At NIV initiation, around $20 \%$ to $50 \%$ of patients with severe CPE are hypercapnic, as defined as a $\mathrm{PaCO}_{2}>45 \mathrm{mmHg}$ [6-12]. Hypercapnia is considered as a marker of severity and has been associated with a higher risk of intubation [14]. Several controlled clinical trials have found that hypercapnia was associated with a poor outcome despite the use of NIV [6, 8]. Factors associated with hypercapnia during $\mathrm{CPE}$ are poorly understood, although many patients with CPE may have an associated underlying chronic lung disease (CLD) promoting hypercapnia. Although some studies excluded patients with a known severe airflow obstruction $[6,8,12]$, some patients may still have non-documented mild or moderate chronic obstructive pulmonary disease (COPD), obesity-hypoventilation syndrome, obstructive sleep apneas, or rib cage abnormalities. The combination of left heart dysfunction and chronic lung disease is common; in a large clinical trial assessing NIV in more than 1000 patients with CPE [2], nearly $20 \%$ of them had an underlying CLD. Conversely, in patients admitted in intensive care unit (ICU) for acute exacerbation of COPD, acute left ventricular dysfunction is identified as the main reason for acute respiratory failure in more than $40 \%$ of the cases [15]. It is well demonstrated that NIV markedly reduces intubation and mortality rates in hypercapnic patients with exacerbation of COPD [16-18]. However, the overall rate of NIV failure in patients with acuteon-chronic lung disease is significantly higher than in those admitted for severe CPE [19] with an intubation rate reaching 25 to $30 \%$ in recent surveys [20, 21].

We therefore conducted this study with the aims (1) to assess the incidence and factors associated with hypercapnia in patients treated by NIV for severe CPE, after excluding all those with any suspected underlying CLD, and (2) to assess the influence of hypercapnia on outcome.

\section{Methods}

The study was conducted in the 24-bed medical ICU at Henri Mondor University hospital in Créteil, France. The study was approved by the Institutional Review Board of the French Society for Respiratory Medicine.

\section{Inclusion of patients with CPE}

During a 3-year period (from June 2008 to June 2011), data on all consecutive patients receiving NIV as initial ventilatory support for acute respiratory failure were included, as previously described [19, 22]. Acute respiratory failure was defined as recent dyspnea with a respiratory rate $>25$ breaths/min and/or sternocleidomastoid muscle activation and/or hypoxemia (defined as a $\mathrm{SpO}_{2}$ below $90 \%$ while breathing room air). The diagnosis of CPE was defined as an acute respiratory failure in a patient with all of the following criteria: a compatible history of prior CPE or chronic heart failure, clinical signs of left and/or right cardiac failure, increase in NT-proBNP above $1000 \mathrm{pg} / \mathrm{ml}$, bilateral alveolar and/or interstitial opacities on chest X-ray, and increase in left ventricular filling pressure on echocardiography indicated by a mitral E/A velocity ratio $>2$ using PW Doppler or E/e' velocity $>15 \mathrm{~cm} / \mathrm{s}$ using tissue Doppler [23], in the absence of pneumonia. Hypercapnia was defined according to the literature [6-12] as a $\mathrm{PaCO}_{2}$ above $45 \mathrm{mmHg}$. All patients with $\mathrm{CPE}$ received concomitant standard medical therapy including vasodilators (repeated boluses of IV isosorbidedinitrate) and diuretics (at least $80 \mathrm{mg}$ of furosemide).

\section{Exclusion of patients with chronic lung disease}

The main reason that led to NIV initiation was systematically recorded by the physician in charge and all patients receiving NIV as initial ventilatory support for acute respiratory failure were then stratified into two subgroups according to their $\mathrm{PaCO}_{2}$ at admission: (1) hypercapnic patients with a $\mathrm{PaCO}_{2}>45 \mathrm{mmHg}$ [19], and (2) hypoxemic non-hypercapnic patients with a $\mathrm{PaCO}_{2}$ $\leq 45 \mathrm{mmHg}$ [22]. For the purpose of the current study, all patients with CPE and documented chronic lung disease were secondarily excluded. An independent pulmonologist $(\mathrm{ACI})$ reviewed all medical charts to exclude patients having any underlying chronic lung disease (CLD), i.e., those with chronic obstructive pulmonary disease, obesity-hypoventilation syndrome, obstructive sleep apnea syndrome (OSA), or another reason for chronic respiratory failure. COPD was suspected on history of smoking, symptoms of chronic bronchitis, dyspnea, and/or chronic hypercapnia, and/or emphysema on chest radiograph or CT scanner. Obesity-hypoventilation syndrome was defined as obesity with a body mass index $>30$ $\mathrm{kg} / \mathrm{m}^{2}$, chronic hypercapnia with a $\mathrm{PaCO}_{2}>45 \mathrm{mmHg}$, in the absence of airflow obstruction using spirometry. Obstructive sleep apneas was defined as apnea-hypopnea index above $10 / \mathrm{h}$ using polysomnography or clinical symptoms using Epworth scale [24], associated with episodes of nocturnal desaturation during their ICU stay. Before and during the study period, several prospective physiological studies have been conducted in our unit to investigate sleep quality using polysomnography in 
patients admitted for acute hypercapnic respiratory failure $[25,26]$. Therefore, special attention was given to identify patients with sleep apneas and polysomnography was usually done before discharge in those with nocturnal desaturation. Hypercapnic patients admitted with acute respiratory failure without documented lung disease were systematically screened and seen 3 months later to perform polysomnography, physiological respiratory tests, thoracic CT scan, and echocardiography, and those having secondarily documented chronic lung disease or airflow obstruction were excluded from this study.

\section{Non-invasive ventilation protocol}

The study was conducted after the implementation, in June 2008, of a nurse-driven NIV protocol which included prospective daily collection of clinical data and ventilatory parameters on a specific NIV monitoring form [19, 22]. NIV was delivered in pressure-support ventilation (PSV) mode with an ICU ventilator using a dedicated NIV mode (Evita XL, Dräger, Lübeck, Germany, or Engström Carestation, GE Healthcare, Fairfield, CT, USA). NIV was started using a PS level of $8 \mathrm{~cm} \mathrm{H}_{2} \mathrm{O}$ and a positive endexpiratory pressure (PEEP) level of $5 \mathrm{~cm} \mathrm{H}_{2} \mathrm{O}$. PSV was gradually increased by $2 \mathrm{~cm} \mathrm{H}_{2} \mathrm{O}$ steps to reach a targeted expiratory tidal volume around $6-8 \mathrm{ml} / \mathrm{kg}$ predicted body weight and $\mathrm{FiO}_{2}$ was gradually adjusted by $5 \%$ step to reach targeted $\mathrm{SpO}_{2} \geq 94 \%$. Non-invasive ventilation was applied intermittently for periods of at least $2 \mathrm{~h}$, with a minimal duration of $6 \mathrm{~h}$ per day, or continuously in case of severe hypoxemia, and was maintained until signs of respiratory distress improved. NIV was delivered via a nonvented full-face mask (Free Motion ${ }^{\text {TM }}$ RT041, Fisher and Paykel, Auckland, New Zealand or Ultra Mirage ${ }^{\mathrm{iw}}$, Resmed, CA, USA). An algorithm was used by nurses in case of leaks, which involved first repositioning of the mask, then reducing the PEEP level at $2 \mathrm{~cm} \mathrm{H}_{2} \mathrm{O}$, third, reducing the pressure-support level by steps of $2 \mathrm{~cm} \mathrm{H}_{2} \mathrm{O}$ until the minimal expiratory volume was reached, and fourth changing the mask interface. A mobile cart containing all types and sizes of interfaces was available at the bedside during initiation of NIV.

\section{Data collection and definitions}

From the NIV monitoring forms, we analyzed the number and duration of NIV sessions, ventilator settings (pressure-support level, positive end-expiratory pressure, $\mathrm{FiO}_{2}$ ), ventilatory parameters $\left(\mathrm{SpO}_{2}\right.$, respiratory rate, expiratory tidal volume), level of consciousness assessed using the Richmond Agitation-Sedation Scale [27], NIV tolerance, amount of leaks, and hemodynamic parameters (heart rate, blood pressure). Blood gases were routinely measured $1 \mathrm{~h}$ after initiation of NIV.

Since CPE is usually characterized by a rapid improvement in respiratory distress within the first hours of therapy, a non-rapid favorable outcome was defined as the need for intubation or for prolonged NIV for more than $48 \mathrm{~h}$. The following criteria were used for tracheal intubation: hypercapnic coma, psychomotor agitation making nursing care impossible and requiring sedation, frank worsening in signs of respiratory distress with a respiratory rate above 40 breaths/min under NIV, $\mathrm{SpO}_{2}$ remaining below $90 \%$ despite $\mathrm{FiO}_{2} 100 \%$, and persistent hypotension. Worsening respiratory acidosis or absolute values of $\mathrm{pH} / \mathrm{PCO}_{2}$ were not used as criteria for intubation in the absence of other signs cited above.

\section{Statistical analysis}

All data are expressed as mean \pm standard deviation $( \pm \mathrm{SD})$ or as median and $\left[25^{\text {th }}-75^{\text {th }}\right]$ percentiles, and dichotomous variables are reported as number and percentage (\%). Qualitative data were compared using the Fisher's exact test, and quantitative data using the Mann-Whitney non-parametric test. To evaluate independent factors associated with non-rapid favorable outcome, we performed a logistic regression analysis using a backward procedure including in the model all nonredundant variables associated with prolonged NIV or intubation with a $p$ value $<0.10$. We considered twotailed $p$ values $<0.05$ as significant. Statistical analyses were performed using the statistical software package STATA version 13.1 (STATA Corp., College Station, TX, USA).

\section{Results}

\section{Patients}

Over a 3-year period, 172 patients received NIV for severe CPE. After excluding 60 patients with associated CLD, 112 patients were retained in the analysis (Fig. 1).

The main precipitating factor for CPE was rapid atrial fibrillation in $9.8 \%$ of the cases $(n=11)$, acute coronary syndrome in $7.1 \%(n=8)$, hypertensive crisis in $12.5 \%$ $(n=14)$, fluid overload in $23.2 \%(n=26)$, respiratory tract infection in $12.5 \%(n=14)$, extra-pulmonary sepsis in $7.1 \%(n=8)$, valvular disease in $4.5 \%(n=5)$, and auricular-ventricular block in $1.7 \%(n=2)$; no precipitating factor was identified in the remaining 24 (21.4\%) patients.

Overall, the rates of intubation (all in the first $24 \mathrm{~h}$ ) and of prolonged NIV $(>48 \mathrm{~h})$ were $6.3 \%(n=7)$ and $21.4 \%(n=24)$, respectively, for a total rate of "nonrapid favorable outcome" of $27.7 \%(n=31)$. Overall inICU mortality was $4 \%$ (4 of the 7 patients who needed intubation, $57 \%$ ).

\section{Characteristics of hypercapnic patients}

Comparisons between hypercapnic patients and nonhypercapnic patients are shown in Table 1. Hypercapnic patients were older, more frequently obese, and were more 


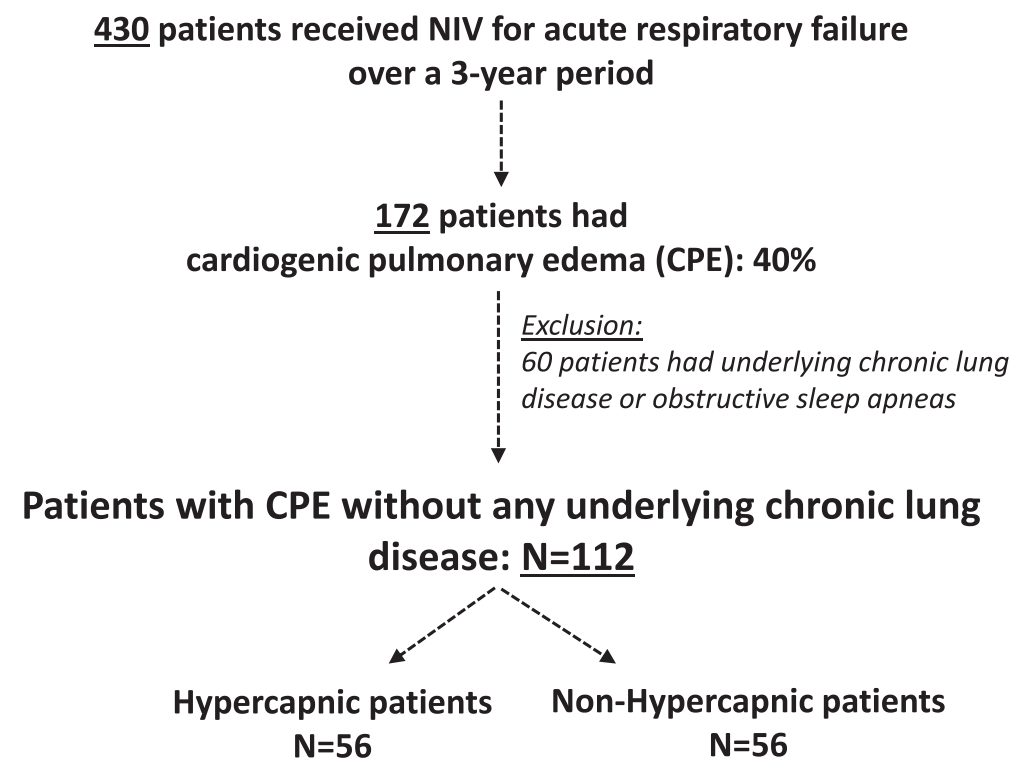

Fig. 1 Flow chart of patients included in this study

likely to have a respiratory tract infection than nonhypercapnic patients. Despite higher pressure-support levels, hypercapnic patients had lower expiratory tidal volume and lower minute ventilation under NIV and had more frequently acidosis and altered mental status. By contrast, non-hypercapnic patients were more hypoxemic and had more frequently tachycardia at admission than hypercapnic patients. Outcomes did not differ between hypercapnic and non-hypercapnic patients (Table 1).

\section{Factors associated with poor outcome}

Comparisons between patients who had a rapid favorable outcome and the others are given in Table 2. Although the proportion of hypercapnic patients at admission $\left(\mathrm{PaCO}_{2}\right.$ $>45 \mathrm{mmHg}$ ) was similar in the two groups, patients with non-rapid favorable outcome had more frequently severe hypercapnia defined as $\mathrm{PaCO}_{2}>60 \mathrm{mmHg}$ (Table 2). After adjustment using logistic regression, the only independent factor associated with non-rapid favorable outcome was severe hypercapnia $\left(\mathrm{PaCO}_{2}>60 \mathrm{mmHg}\right)$, at admission $(\mathrm{OR}=4.15$ [95 \% CI 1.62-10.6]; $p=0.003)$. The need for intubation was uncommon and did not differ between patients with severe hypercapnia at admission and the others with a rate of only $8 \%(2 / 25)$ vs. $6 \%(5 / 87), p=0.65$, respectively. However, patients with severe hypercapnia were more likely to receive prolonged NIV than patients with no or moderate hypercapnia (Fig. 2). As shown Fig. 3, the durations of NIV and of ICU stay were both prolonged by a median of 1 day in patients with severe hypercapnia as compared to the others (2.0 days [1.0-3.0] vs. 1.0 $[1.0-2.0], p=0.003$, and 5.0 days [3.0-7.0] vs. 4.0 [2.0-5.5], $p=0.03$, respectively). Patients with severe hypercapnia at admission had lower $\mathrm{pH}$ values and a higher $\mathrm{PaCO}_{2}$ than the others patients $24 \mathrm{~h}$ after NIV initiation: $(7.36 \pm 0.08$ vs. $7.46 \pm 0.06$, and $60 \pm 15 \mathrm{mmHg}$ vs. $38 \pm 7, p<0.001$ for both).

In patients with a history of smoking or with a BMI $>30$ $\mathrm{kg} / \mathrm{m}^{2}$, the rate of non-rapid favorable outcome was similar to that observed in patients without none of these two risk factors for chronic lung disease, $28 \%(15 / 53)$ vs. $27 \%$ (16/59), respectively, $p>0.99$.

\section{Discussion}

We assessed the role of hypercapnia on outcome of patients treated with NIV for severe CPE and having no identified underlying chronic lung disease. We found that half of the patients had hypercapnia at admission. Hypercapnic patients were older, more frequently obese, had more frequently infection of respiratory tract, and had lower tidal volumes despite higher pressure-support levels. Outcome was similar between hypercapnic and nonhypercapnic patients. However, patients with severe hypercapnia $\left(\mathrm{PaCO}_{2}>60 \mathrm{mmHg}\right)$ at admission required a longer duration of NIV without increase in intubation rate.

\section{Incidence and factors associated to hypercapnia}

Our study shows that half of the patients with severe CPE had hypercapnia upon ICU admission. Although no previous studies has systematically excluded all patients with any underlying chronic lung disease as we did, this $50 \%$ rate is in keeping with the literature reporting a 40 to $50 \%$ proportion of hypercapnic patients among those admitted with CPE [7, 8, 10-12, 14]. Despite higher pressure-support levels during NIV, hypercapnic patients had lower tidal volumes and appeared therefore unable to increase minute ventilation to compensate for hypercapnia. 
Table 1 Comparison of patients according to the presence or not of hypercapnia at admission

\begin{tabular}{|c|c|c|c|}
\hline & $\begin{array}{l}\text { Non-hypercapnic, } \\
N=56\end{array}$ & $\begin{array}{l}\text { Hypercapnic, } \\
N=56\end{array}$ & $P$ value \\
\hline \multicolumn{4}{|l|}{ Characteristics of the patients } \\
\hline Age, years & $68.7 \pm 14.0$ & $76.6 \pm 11.8$ & $<0.01$ \\
\hline Male gender, $n(\%)$ & $26(46 \%)$ & $30(54 \%)$ & 0.71 \\
\hline SAPS II, points & $36.5 \pm 12.5$ & $39.1 \pm 14.1$ & 0.38 \\
\hline $\mathrm{BMI}, \mathrm{kg} / \mathrm{m}^{2}$ & $24.7 \pm 6.1$ & $27.0 \pm 5.6$ & 0.03 \\
\hline $\mathrm{BMI}>30 \mathrm{~kg} / \mathrm{m}^{2}, n(\%)$ & $4 / 47(9 \%)$ & 14/45 (31 \%) & $<0.01$ \\
\hline $\begin{array}{l}\text { History of smoking, } \\
n(\%)\end{array}$ & $16(29 \%)$ & $24(43 \%)$ & 0.17 \\
\hline $\begin{array}{l}\text { Underlying ischemic } \\
\text { cardiopathy, } n(\%)\end{array}$ & $30(54 \%)$ & $25(45 \%)$ & 0.35 \\
\hline Baseline LVEF, \% & $41 \pm 15$ & $42 \pm 12$ & 0.84 \\
\hline \multicolumn{4}{|l|}{ Reason for CPE } \\
\hline Atrial fibrillation, $n(\%)$ & $7(12.5)$ & $4(7.1 \%)$ & 0.52 \\
\hline $\begin{array}{l}\text { Acute myocardial } \\
\text { infarction, } n(\%)\end{array}$ & $3(5.4 \%)$ & $5(8.9 \%)$ & 0.71 \\
\hline $\begin{array}{l}\text { Hypertensive crisis, } \\
n(\%)\end{array}$ & $8(14.3)$ & $6(10.7 \%)$ & 0.77 \\
\hline Fluid overload, $n$ (\%) & 17 (30.4 \%) & $9(16.1 \%)$ & 0.12 \\
\hline $\begin{array}{l}\text { Respiratory tract } \\
\text { infection, } n(\%)\end{array}$ & $3(5.4 \%)$ & $11(19.6 \%)$ & 0.04 \\
\hline $\begin{array}{l}\text { Unidentified factor, } \\
n(\%)\end{array}$ & 10 (17.9\%) & $14(25.0)$ & 0.49 \\
\hline Other, $n(\%)$ & $8(14.3 \%)$ & $7(12.5 \%)$ & $>0.99$ \\
\hline \multicolumn{4}{|l|}{ At admission } \\
\hline $\begin{array}{l}\text { Respiratory rate, } \\
\text { cycles/min }\end{array}$ & $32 \pm 7$ & $32 \pm 7$ & 0.77 \\
\hline Heart rate, beats/min & $109 \pm 28$ & $96 \pm 20$ & $<0.01$ \\
\hline $\begin{array}{l}\text { Systolic blood pressure, } \\
\mathrm{mmHg}\end{array}$ & $151 \pm 35$ & $157 \pm 36$ & 0.33 \\
\hline $\begin{array}{l}\text { Glasgow coma scale, } \\
\text { points }\end{array}$ & $14.8 \pm 0.7$ & $14.0 \pm 2.5$ & 0.08 \\
\hline $\mathrm{pH}$, units & $7.40 \pm 0.06$ & $7.25 \pm 0.10$ & $<0.01$ \\
\hline $\mathrm{pH}<7.35, n(\%)$ & $10(18 \%)$ & 44 (79 \%) & $<0.01$ \\
\hline $\mathrm{PaO}_{2}, \mathrm{mmHg}$ & $87 \pm 45$ & $120 \pm 80$ & $<0.01$ \\
\hline $\mathrm{PaCO}_{2}, \mathrm{mmHg}$ & $36 \pm 5$ & $63 \pm 16$ & $<0.01$ \\
\hline Bicarbonates, mmol/L & $23.2 \pm 3.8$ & $29.0 \pm 6.9$ & $<0.01$ \\
\hline $\begin{array}{l}\text { N-terminal pro-BNP, } \\
\mathrm{ng} / \mathrm{L}\end{array}$ & $20720 \pm 36085$ & $23,003 \pm 39,928$ & 0.59 \\
\hline Troponin, $\mu \mathrm{g} / \mathrm{L}$ & $0.296 \pm 1.053$ & $0.207 \pm 0.925$ & 0.11 \\
\hline \multicolumn{4}{|l|}{ At initiation of NIV } \\
\hline $\begin{array}{l}\text { Respiratory rate, } \\
\text { cycles/min }\end{array}$ & $30 \pm 7$ & $30 \pm 8$ & 0.98 \\
\hline Heart rate, beats/min & $105 \pm 24$ & $93 \pm 20$ & 0.01 \\
\hline $\begin{array}{l}\text { Systolic blood pressure, } \\
\mathrm{mmHg}\end{array}$ & $136 \pm 25$ & $144 \pm 34$ & 0.22 \\
\hline $\begin{array}{l}\text { Altered consciousness } \\
(\text { RASS }<0), n(\%)\end{array}$ & $2(4 \%)$ & $11(20 \%)$ & 0.02 \\
\hline
\end{tabular}

Table 1 Comparison of patients according to the presence or not of hypercapnia at admission (Continued)

\begin{tabular}{|c|c|c|c|}
\hline $\mathrm{FiO}_{2}, \%$ & $67 \pm 24$ & $60 \pm 27$ & 0.21 \\
\hline PEEP level, $\mathrm{cm} \mathrm{H}_{2} \mathrm{O}$ & $4.9 \pm 1.7$ & $4.6 \pm 1.8$ & 0.35 \\
\hline $\begin{array}{l}\text { Pressure-support level, } \\
\mathrm{Cm} \mathrm{H}_{2} \mathrm{O}\end{array}$ & $7.9 \pm 1.8$ & $10.0 \pm 2.7$ & $<0.01$ \\
\hline $\begin{array}{l}\text { Expiratory tidal volume, } \\
\mathrm{ml}\end{array}$ & $604 \pm 172$ & $496 \pm 125$ & $<0.01$ \\
\hline $\mathrm{pH}$, units & $7.42 \pm 0.09$ & $7.35 \pm 0.08$ & $<0.01$ \\
\hline $\begin{array}{l}\text { Minute ventilation, } \\
\mathrm{L} / \mathrm{min}\end{array}$ & $17.6 \pm 6.0$ & $14.5 \pm 5.4$ & 0.02 \\
\hline $\mathrm{PaCO}_{2}, \mathrm{mmHg}$ & $37 \pm 9$ & $51 \pm 13$ & $<0.01$ \\
\hline $\mathrm{PaO}_{2} / \mathrm{FiO}_{2}, \mathrm{mmHg}$ & $247 \pm 108$ & $234 \pm 88$ & 0.68 \\
\hline $\begin{array}{l}\text { Leaks or poor tolerance, } \\
n(\%)\end{array}$ & 5/43 (19\%) & $10 / 41(15 \%)$ & 0.16 \\
\hline \multicolumn{4}{|l|}{ Patients' outcome } \\
\hline NIV duration, days & $1.0[1.0-2.0]$ & $2.0[1.0-3.0]$ & 0.14 \\
\hline $\begin{array}{l}\text { ICU Length of stay, } \\
\text { days }\end{array}$ & $4.0[2.8-6.0]$ & $4.0[2.8-6.3]$ & 0.97 \\
\hline $\begin{array}{l}\text { Non-rapid favorable } \\
\text { outcome, } n(\%)\end{array}$ & $13(23.2 \%)$ & 18 (32.1\%) & 0.40 \\
\hline $\begin{array}{l}\text { Prolonged NIV (>48 h), } \\
n(\%)\end{array}$ & $9(16.1 \%)$ & 15 (26.8 \%) & 0.25 \\
\hline Intubation, n (\%) & 4 (7.1\%) & $3(5.4 \%)$ & $>0.99$ \\
\hline In-ICU mortality, n (\%) & 2 (3.6\%) & $2(3.6 \%)$ & $>0.99$ \\
\hline
\end{tabular}

A small tidal volume suggests a weak patient effort or an altered compliance of the respiratory system. In the absence of CLD, hypercapnic patients were older and more frequently obese than non-hypercapnic patients. Whereas elderly patients might rapidly suffer from muscle weakness and diaphragmatic fatigue and therefore generate weak inspiratory efforts, obese patients have marked reduction in compliance in respiratory system due to increased abdominal pressure and stiff thoracic cage, reducing tidal volumes and promoting hypercapnia. These two factors, associated to extensive airway collapse and/or obstruction by alveolar edema fluid, can promote hypercapnia and may concur to the inability to maintain adequate alveolar ventilation.

\section{Role of hypercapnia on outcome}

We found that hypercapnia upon admission did not influence outcome. However, severe hypercapnia $\left(\mathrm{PaCO}_{2}\right.$ $>60 \mathrm{mmHg}$ ) at admission was associated with a nonrapid favorable outcome, although the rate of intubation did not differ and the only difference between patients with severe hypercapnia and the others was the need for longer duration of NIV and of ICU stay by only 1 day. Several studies found an increased rate of intubation in hypercapnic patients as compared to non-hypercapnic 
Table 2 Comparison of patients according to outcome

\begin{tabular}{|c|c|c|c|}
\hline & $\begin{array}{l}\text { Rapid favorable } \\
\text { outcome, } \\
N=81\end{array}$ & $\begin{array}{l}\text { Non-favorable } \\
\text { outcome, } \\
N=31\end{array}$ & $P$ value \\
\hline \multicolumn{4}{|l|}{ Characteristics of the patients } \\
\hline Age, years & $71.9 \pm 13.1$ & $76.7 \pm 14.6$ & 0.21 \\
\hline Male gender, $n(\%)$ & $42(52 \%)$ & $15(48 \%)$ & 0.83 \\
\hline SAPS II, points & $36.2 \pm 11.8$ & $41.9 \pm 16.1$ & 0.06 \\
\hline $\mathrm{BMI}, \mathrm{kg} / \mathrm{m}^{2}$ & $25.7 \pm 5.7$ & $26.3 \pm 6.5$ & 0.94 \\
\hline Smoker, $n$ (\%) & $28(35 \%)$ & $12(39 \%)$ & 0.83 \\
\hline $\begin{array}{l}\text { Underlying ischemic } \\
\text { cardiopathy, } n(\%)\end{array}$ & $40(49 \%)$ & $15(48 \%)$ & $>0.99$ \\
\hline LVEF, \% & $41 \pm 14$ & $42 \pm 14$ & 0.69 \\
\hline \multicolumn{4}{|l|}{ Reason for CPE } \\
\hline Atrial fibrillation, $n(\%)$ & $8(9.9 \%)$ & $3(9.7 \%)$ & $>0.99$ \\
\hline $\begin{array}{l}\text { Acute myocardial infarction, } \\
n(\%)\end{array}$ & $8(9.9 \%)$ & 0 & 0.10 \\
\hline Hypertensive crisis, $n$ (\%) & $11(13.6 \%)$ & $3(9.7 \%)$ & 0.75 \\
\hline Overload, $n(\%)$ & $21(25.9 \%)$ & $5(16.1 \%)$ & 0.33 \\
\hline $\begin{array}{l}\text { Infection of respiratory tract, } \\
n(\%)\end{array}$ & $8(9.9 \%)$ & $6(19.4 \%)$ & 0.21 \\
\hline Other, $n(\%)$ & $8(9.9 \%)$ & 7 (22.6 \%) & 0.12 \\
\hline Unidentified factor, $n(\%)$ & $17(21.0 \%)$ & $7(22.6 \%)$ & $>0.99$ \\
\hline \multicolumn{4}{|l|}{ At admission } \\
\hline Respiratory rate, cycles/min & $32 \pm 7$ & $32 \pm 6$ & 0.96 \\
\hline Heart rate, beats/min & $102 \pm 27$ & $103 \pm 19$ & 0.69 \\
\hline $\begin{array}{l}\text { Systolic blood pressure, } \\
\mathrm{mmHg}\end{array}$ & $154 \pm 37$ & $153 \pm 32$ & 0.93 \\
\hline Glasgow coma scale, points & $14.5 \pm 1.9$ & $14.3 \pm 1.9$ & 0.16 \\
\hline $\mathrm{pH}$, units & $7.33 \pm 0.11$ & $7.31 \pm 0.11$ & 0.27 \\
\hline $\mathrm{PaO}_{2}, \mathrm{mmHg}$ & $100 \pm 60$ & $113 \pm 81$ & 0.64 \\
\hline $\mathrm{PaCO}_{2}, \mathrm{mmHg}$ & $47 \pm 15$ & $55 \pm 22$ & 0.16 \\
\hline $\mathrm{PaCO}_{2}>45$ mmHg, $n(\%)$ & $38(47 \%)$ & $18(58 \%)$ & 0.40 \\
\hline $\mathrm{PaCO}_{2}>60$ mmHg, $n(\%)$ & $12(15 \%)$ & $13(42 \%)$ & $<0.01$ \\
\hline Bicarbonates, $\mathrm{mmol} / \mathrm{L}$ & $25.3 \pm 4.7$ & $28.0 \pm 8.8$ & 0.25 \\
\hline N-terminal pro-BNP, ng/L & $\begin{array}{l}21,398 \pm \\
37,463\end{array}$ & $\begin{array}{l}23,115 \pm \\
39,739\end{array}$ & 0.48 \\
\hline Troponin, $\mu \mathrm{g} / \mathrm{L}$ & $0.22 \pm 0.88$ & $0.32 \pm 1.21$ & 0.67 \\
\hline \multicolumn{4}{|l|}{ At initiation of NIV } \\
\hline Heart rate, beats/min & $100 \pm 25$ & $98 \pm 19$ & 0.70 \\
\hline $\begin{array}{l}\text { Systolic blood pressure, } \\
\mathrm{mmHg}\end{array}$ & $142 \pm 32$ & $136 \pm 26$ & 0.66 \\
\hline $\begin{array}{l}\text { Altered consciousness } \\
(\text { RASS <0), } n(\%)\end{array}$ & $8(10 \%)$ & $5(16 \%)$ & 0.51 \\
\hline Respiratory rate, cycles/min & $30 \pm 8$ & $30 \pm 6$ & 0.92 \\
\hline Expiratory tidal volume, $\mathrm{ml}$ & $568 \pm 151$ & $513 \pm 114$ & 0.047 \\
\hline Minute ventilation, L/min & $16.4 \pm 5.6$ & $15.3 \pm 6.4$ & 0.25 \\
\hline $\begin{array}{l}\text { Pressure-support level, } \\
\mathrm{cm} \mathrm{H}_{2} \mathrm{O}\end{array}$ & $8.2 \pm 1.9$ & $10.2 \pm 2.9$ & $<0.01$ \\
\hline PEEP level, $\mathrm{cm} \mathrm{H}_{2} \mathrm{O}$ & $4.8 \pm 1.7$ & $4.7 \pm 1.8$ & 0.60 \\
\hline
\end{tabular}

Table 2 Comparison of patients according to outcome (Continued)

\begin{tabular}{llll}
\hline $\mathrm{FiO}_{2}, \%$ & $66 \pm 25$ & $59 \pm 27$ & 0.27 \\
$\mathrm{pH}$, units & $7.40 \pm 0.09$ & $7.36 \pm 0.08$ & 0.015 \\
$\mathrm{PaCO}_{2}, \mathrm{mmHg}$ & $41 \pm 11$ & $50 \pm 16$ & 0.017 \\
$\mathrm{PaCO}_{2}>45 \mathrm{mmHg}$ & $11 / 71(15 \%)$ & $16 / 31(52 \%)$ & $<0.01$ \\
$\mathrm{PaO}_{2} / \mathrm{FiO}_{2}, \mathrm{mmHg}$ & $243 \pm 99$ & $235 \pm 98$ & 0.67 \\
$\mathrm{PaO}_{2} / \mathrm{FiO}_{2} \leq 200 \mathrm{mmHg}$ & $27 / 71(38 \%)$ & $10 / 31(32 \%)$ & 0.66 \\
Patients' outcome & & & \\
$\mathrm{NIV}$ duration, days & $1.0[1.0-2.0]$ & $3.0[3.0-4.0]$ & $<0.01$ \\
ICU Length of stay, days & $3.0[2.0-5.0]$ & $7.0[5.0-9.5]$ & $<0.01$ \\
\hline
\end{tabular}

Abbreviations: SAPS simplified acute physiological score, BMI body mass index, LVEF left ventricular ejection fraction, CPE cardiogenic pulmonary edema, NIV non-invasive ventilation, RASS Richmond agitation-sedation scale, PEEP positive end-expiratory pressure, ICU intensive care unit

patients [6, 14]. Although all patients received NIV, Nouira and colleagues found a $20 \%$ intubation rate in hypercapnic patients vs. only $4 \%$ in the others [6]. The impact of hypercapnia on outcome must be analyzed with caution since most of studies did not exclude patients with CLD which may confound the interpretation.

NIV can be delivered using continuous positive airway pressure (CPAP) or using bi-level positive airway pressure with pressure-support (PS). Whatever the ventilation strategy used, positive airway pressure improves cardiac performance by decreasing preload and afterload [28], and improves respiratory function by decreasing work of breathing [29], resulting a rapid improvement in oxygenation. However, PSV is particularly effective in hypercapnic patients, and several studies found that respiratory distress improved more rapidly using PSV than using CPAP $[2,6]$. Contrarily to the above-mentioned

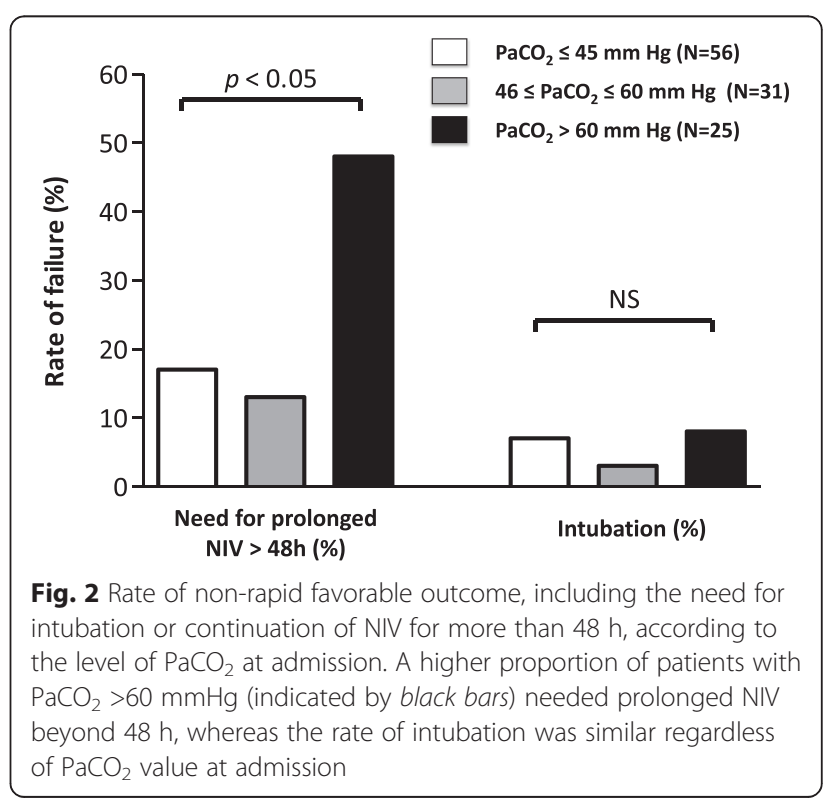




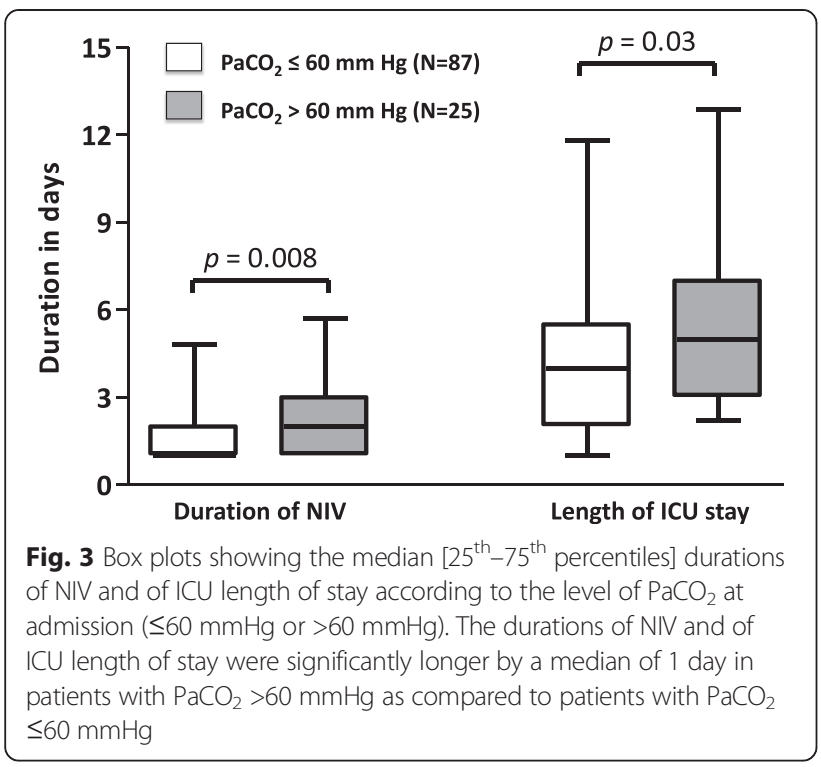

studies, one study has suggested that hypercapnic patients treated using PSV may have a better outcome than non-hypercapnic patients [7]. However, in that study, the rate of intubation was as expected in hypercapnic patients (6\%), whereas it was exceedingly high (34\%) in non-hypercapnic patients. With the use of PSV, we found no difference in intubation rate between hypercapnic and non-hypercapnic patients, in keeping with another study showing that acidemia whether respiratory or metabolic upon admission had no impact on outcome [10]. We also found no difference in terms of blood pressure between patients with non-rapid favorable outcome and the others, whereas a lower systolic arterial blood pressure had been associated to worst outcome in a previous study [30].

\section{Clinical implications}

Although hypercapnia usually defined as $\mathrm{PaCO}_{2}>45$ $\mathrm{mmHg}$ at admission had no influence on outcome, clinicians should be aware that patients with $\mathrm{CPE}$ presenting with severe hypercapnia $\left(\mathrm{PaCO}_{2}>60 \mathrm{mmHg}\right)$ may require more prolonged NIV than those with no or moderate hypercapnia. Whereas the rate of intubation in patients with obesity-hypoventilation is close to that reported in CPE [31], i.e., below $10 \%$, several controlled trials reported a rate of intubation between 20 and $30 \%$ in COPD patients treated by NIV [16, 32, 33]. Therefore, an underlying CLD or obstructive sleep apneas should be systematically suspected in patients with CPE requiring intubation or prolonged NIV.

\section{Limitations}

Our study has several limitations. First, it was conducted in a single unit with a long-standing experience in the practice of NIV, and therefore our results may not be applicable to other centers. Second, some hypercapnic patients included may still have underlying CLD leading to potential alveolar hypoventilation. However, among hypercapnic patients, most of them (57\%) had never smoked making it unlikely to have COPD while $69 \%$ of them had a body mass index below $30 \mathrm{~kg} / \mathrm{cm}^{2}$ excluding obesity-hypoventilation syndrome. Moreover, we put substantial efforts during this study in identifying patients having underlying CLD and sleep apneas. We arbitrarily defined non-rapid favorable outcome as the need for NIV longer than $48 \mathrm{~h}$ which identified the worst quartile of patients needing longer duration of NIV. Although no criterion is established to define a rapid favorable outcome, CPE is usually rapidly reversible the first $24 \mathrm{~h}$ of therapy. Lastly, given that intubation was an uncommon event, we could not analyze the independent risk factors of poor outcome and consequently the real impact of hypercapnia on outcome. Although all our patients with acute myocardial infarction had a rapid favorable outcome, the number of patients was too small to highlight a potential difference.

\section{Conclusions}

Hypercapnia occurred in half of the patients among the most severe admitted to the ICU for CPE, even after excluding all those with any underlying CLD. Hypercapnic patients were older and were more frequently obese. The rates of intubation or prolonged NIV for more than $48 \mathrm{~h}$ were similar between hypercapnic and non-hypercapnic patients. However, patients with severe hypercapnia required longer durations of NIV and ICU stay.

\section{Abbreviations}

CLD: Chronic lung disease; COPD: Chronic obstructive pulmonary disease: CPAP: Continuous positive airway pressure; CPE: Cardiogenic pulmonary edema; ICU: Intensive care unit; OSA: Obstructive sleep apnea; NIV: Non-invasive ventilation; PEEP: Positive end-expiratory pressure.

\section{Competing interests}

The authors declare that they have no competing interests.

\section{Authors' contributions}

AWT, DC, and CBB conceived the study. DC, CF, FB, and ACl collected the data. AWT made the statistical analysis. DC, AWT, and CBB drafted the manuscript, and all authors contributed substantially to its revision. DC takes responsibility for the paper as a whole. All authors read and approved the final manuscript.

\section{Acknowledgements}

This study did not receive funding from external or internal sources.

\section{Author details}

${ }^{1}$ AP-HP, Réanimation Médicale, Groupe Hospitalier Henri Mondor - Albert Chenevier, Créteil, France. ${ }^{2}$ Réanimation Médicale, CHU de Poitiers, 2 rue de la Milétrie, 86021 Poitiers, France. ${ }^{3}$ INSERM CIC 1402 (ALIVE group), Université de Poitiers, Poitiers, France.

Received: 6 January 2015 Accepted: 26 May 2015

Published online: 07 June 2015 


\section{References}

1. Cotter G, Metzkor E, Kaluski E, Faigenberg Z, Miller R, Simovitz A, et al. Randomised trial of high-dose isosorbide dinitrate plus low-dose furosemide versus high-dose furosemide plus low-dose isosorbide dinitrate in severe pulmonary oedema. Lancet. 1998;351(9100):389-93. PubMed.

2. Gray A, Goodacre S, Newby DE, Masson M, Sampson F, Nicholl J, et al. Noninvasive ventilation in acute cardiogenic pulmonary edema. N Engl J Med. 2008;359(2):142-51. PubMed.

3. Masip J, Roque M, Sanchez B, Fernandez R, Subirana M, Exposito JA. Noninvasive ventilation in acute cardiogenic pulmonary edema: systematic review and meta-analysis. JAMA. 2005;294(24):3124-30. PubMed Epub 2005/12/29. eng.

4. Peter JV, Moran JL, Phillips-Hughes J, Graham P, Bersten AD. Effect of non-invasive positive pressure ventilation (NIPPV) on mortality in patients with acute cardiogenic pulmonary oedema: a meta-analysis. Lancet. 2006;367(9517):1155-63. PubMed.

5. Vital FM, Saconato H, Ladeira MT, Sen A, Hawkes CA, Soares B, et al. Non-invasive positive pressure ventilation (CPAP or bilevel NPPV) for cardiogenic pulmonary edema. Cochrane Database Syst Rev. 2008 (3):CD005351. PubMed

6. Nouira S, Boukef R, Bouida W, Kerkeni W, Beltaief K, Boubaker H, et al Non-invasive pressure support ventilation and CPAP in cardiogenic pulmonary edema: a multicenter randomized study in the emergency department. Intensive Care Med. 2011;37(2):249-56. PubMed Epub 2010/12/08. eng.

7. Nava S, Carbone G, DiBattista N, Bellone A, Baiardi P, Cosentini R, et al. Noninvasive ventilation in cardiogenic pulmonary edema: a multicenter randomized trial. Am J Respir Crit Care Med. 2003;168(12):1432-7. PubMed Epub 2003/09/06. eng.

8. Moritz F, Brousse B, Gellee B, Chajara A, L'Her E, Hellot MF, et al. Continuous positive airway pressure versus bilevel noninvasive ventilation in acute cardiogenic pulmonary edema: a randomized multicenter trial. Ann Emerg Med. 2007:50(6):666-75. 75 e1. PubMed Epub 2007/09/04. eng.

9. Park M, Sangean MC, Volpe Mde S, Feltrim MI, Nozawa E, Leite PF, et al. Randomized, prospective trial of oxygen, continuous positive airway pressure, and bilevel positive airway pressure by face mask in acute cardiogenic pulmonary edema. Crit Care Med. 2004;32(12):2407-15. PubMed.

10. Aliberti S, Piffer F, Brambilla AM, Bignamini AA, Rosti VD, Maraffi T, et al. Acidemia does not affect outcomes of patients with acute cardiogenic pulmonary edema treated with continuous positive airway pressure. Crit Care. 2010;14(6):R196. PubMed Pubmed Central PMCID: 3220020.

11. L'Her E, Duquesne F, Girou E, de Rosiere XD, Le Conte P, Renault S, et al. Noninvasive continuous positive airway pressure in elderly cardiogenic pulmonary edema patients. Intensive Care Med. 2004;30(5):882-8. PubMed Epub 2004/03/03. eng.

12. Masip J, Betbese AJ, Paez J, Vecilla F, Canizares R, Padro J, et al. Non-invasive pressure support ventilation versus conventional oxygen therapy in acute cardiogenic pulmonary oedema: a randomised trial. Lancet. 2000;356(9248):2126-32. PubMed Epub 2001/02/24. eng.

13. Aberman A, Fulop M. The metabolic and respiratory acidosis of acute pulmonary edema. Ann Intern Med. 1972;76(2):173-84. PubMed.

14. Masip J, Paez J, Merino M, Parejo S, Vecilla F, Riera C, et al. Risk factors for intubation as a guide for noninvasive ventilation in patients with severe acute cardiogenic pulmonary edema. Intensive Care Med. 2003;29(11):1921-8. PubMed.

15. Abroug F, Ouanes-Besbes L, Nciri N, Sellami N, Addad F, Hamda KB, et al. Association of left-heart dysfunction with severe exacerbation of chronic obstructive pulmonary disease: diagnostic performance of cardiac biomarkers. Am J Respir Crit Care Med. 2006;174(9):990-6. PubMed.

16. Brochard L, Mancebo J, Wysocki M, Lofaso F, Conti G, Rauss A, et al. Noninvasive ventilation for acute exacerbations of chronic obstructive pulmonary disease. N Engl J Med. 1995;333(13):817-22. PubMed.

17. Lightowler JV, Wedzicha JA, Elliott MW, Ram FS. Non-invasive positive pressure ventilation to treat respiratory failure resulting from exacerbations of chronic obstructive pulmonary disease: Cochrane systematic review and meta-analysis. BMJ. 2003;326(7382):185. PubMed Epub 2003/01/25. eng.

18. Keenan SP, Sinuff T, Cook DJ, Hill NS. Which patients with acute exacerbation of chronic obstructive pulmonary disease benefit from noninvasive positive-pressure ventilation? A systematic review of the literature. Ann Intern Med. 2003;138(11):861-70. PubMed Epub 2003/06/05. eng.
19. Contou D, Fragnoli C, Cordoba-Izquierdo A, Boissier F, Brun-Buisson C, Thille AW. Noninvasive ventilation for acute hypercapnic respiratory failure: intubation rate in an experienced unit. Respir Care. 2013;58(12):2045-52. PubMed.

20. Demoule A, Girou E, Richard JC, Taille S, Brochard L. Increased use of noninvasive ventilation in French intensive care units. Intensive Care Med. 2006;32(11):1747-55. PubMed.

21. Ozsancak Ugurlu A, Sidhom SS, Khodabandeh A, leong M, Mohr C, Lin DY, et al. Use and outcomes of noninvasive positive pressure ventilation in acute care hospitals in Massachusetts. Chest. 2014;145(5):964-71. PubMed.

22. Thille AW, Contou D, Fragnoli C, Cordoba-lzquierdo A, Boissier F, Brun-Buisson C. Non-invasive ventilation for acute hypoxemic respiratory failure: intubation rate and risk factors. Crit Care. 2013;17(6):R269. PubMed.

23. Nagueh SF, Appleton CP, Gillebert TC, Marino PN, Oh JK, Smiseth OA, et al. Recommendations for the evaluation of left ventricular diastolic function by echocardiography. Eur J Echocardiogr. 2009;10(2):165-93. PubMed.

24. Johns MW. A new method for measuring daytime sleepiness: the Epworth sleepiness scale. Sleep. 1991;14(6):540-5. PubMed.

25. Cordoba-Izquierdo A, Drouot X, Thille AW, Galia F, Roche-Campo F, Schortgen $F$, et al. Sleep in hypercapnic critical care patients under noninvasive ventilation: conventional versus dedicated ventilators. Crit Care Med. 2013;41(1):60-8. PubMed Epub 2012/12/12. eng.

26. Roche Campo F, Drouot X, Thille AW, Galia F, Cabello B, D'Ortho MP, et al. Poor sleep quality is associated with late noninvasive ventilation failure in patients with acute hypercapnic respiratory failure. Crit Care Med. 2010;38(2):477-85. PubMed Epub 2009/10/01. eng.

27. Ely EW, Truman B, Shintani A, Thomason JW, Wheeler AP, Gordon S, et al. Monitoring sedation status over time in ICU patients: reliability and validity of the Richmond Agitation-Sedation Scale (RASS). JAMA. 2003;289(22):2983-91. PubMed Epub 2003/06/12. eng.

28. Mehta S, Liu PP, Fitzgerald FS, Allidina YK, Douglas BT. Effects of continuous positive airway pressure on cardiac volumes in patients with ischemic and dilated cardiomyopathy. Am J Respir Crit Care Med. 2000;161(1):128-34. PubMed.

29. Katz JA, Marks JD. Inspiratory work with and without continuous positive airway pressure in patients with acute respiratory failure. Anesthesiology. 1985;63(6):598-607. PubMed.

30. Di Marco F, Tresoldi S, Maggiolini S, Bozzano A, Bellani G, Pesenti A, et al. Risk factors for treatment failure in patients with severe acute cardiogenic pulmonary oedema. Anaesth Intensive Care. 2008;36(3):351-9. PubMed Epub 2008/06/21. eng.

31. Carrillo A, Ferrer M, Gonzalez-Diaz G, Lopez-Martinez A, Llamas N, Alcazar M, et al. Noninvasive ventilation in acute hypercapnic respiratory failure caused by obesity hypoventilation syndrome and chronic obstructive pulmonary disease. Am J Respir Crit Care Med. 2012;186(12):1279-85. PubMed.

32. Jolliet P, Tassaux D, Roeseler J, Burdet L, Broccard A, D'Hoore W, et al. Helium-oxygen versus air-oxygen noninvasive pressure support in decompensated chronic obstructive disease: a prospective, multicenter study. Crit Care Med. 2003;31(3):878-84. PubMed Epub 2003/03/11. eng.

33. Maggiore SM, Richard JC, Abroug F, Diehl JL, Antonelli M, Sauder P, et al. A multicenter, randomized trial of noninvasive ventilation with helium-oxygen mixture in exacerbations of chronic obstructive lung disease. Crit Care Med. 2010;38(1):145-51. PubMed.

\section{Submit your manuscript to a SpringerOpen ${ }^{\circ}$ journal and benefit from:}

- Convenient online submission

Rigorous peer review

- Immediate publication on acceptance

- Open access: articles freely available online

- High visibility within the field

- Retaining the copyright to your article

Submit your next manuscript at $>$ springeropen.com 